\title{
FABRICATION OF OIL EXTRACTION MACHINE FROM JATROPHA SEEDS AND BLENDING PROCESS FOR BIODIESEL
}

\author{
A K Murthy \\ Dean Academics, Department of M.E, AMC Engineering College, Bangalore, India \\ Girisha.C \\ HOD, AMC Engineering College, Bangalore, India \\ Mohammed Imran, Arvind Swamy G, Kripesh B, Mukesh S P \\ Students, Department of M.E, AMC Engineering College, Bangalore, India
}

\begin{abstract}
Diminishing fossil fuel resources, unstable/increasing prices of oil, environmental issues, global warming/climatic shifts, and allied problems have led the world to focus on alternate, environmental friendly, and renewable energy sources. Among many experimental candidates, production of biodiesel from Jatropha curcas L. has gained significant importance. More than 40 countries in the world are evaluating the potential of using this pure plant oil for manufacturing diesel. Biodiesel is a fuel type that has already been proven suitable for use in diesel engines. The non-edible vegetable oil of Jatropha curcas, which grows in tropical and subtropical climates across the developing world, promises a commercially viable alternative to diesel. Jatropha oil is renewable, environmental friendly and can be easily produced in rural areas. Countries of South-East Asia, such as Malaysia, they are going to start the establishment of Jatropha plantations assuming that Jatropha will be the main resource for biodiesel production. This paper presents the design and fabrication of an efficient Jatropha oil expelling machine. Further carrying out transesterification process on Jatropha oil to get Jatropha biodiesel.
\end{abstract}

Cite this Article: A K Murthy, Girisha.C, Mohammed Imran, Arvind Swamy G, Kripesh B and Mukesh S P, Fabrication of Oil Extraction Machine from Jatropha Seeds and Blending Process for Biodiesel, International Journal of Advanced Research in Engineering and Technology, 10(3), 2019, pp 11-26.

http://iaeme.com/Home/issue/IJARET?Volume $=10 \&$ Issue $=3$ 


\section{INTRODUCTION}

Energy is the source of life, however there is a limited supply of energy on earth. Thus, renewable energy utilization must be widespread all over the world otherwise the end of life would be unavoidable. One other important reason to prefer renewable energy is the environmental pollution depending on the emission of the burning of fossil fuels. These emissions such as carbon dioxide and sulphur cause greenhouse effect which lead to contamination and warming of the Earth.

Therefore, the utilization technologies of the renewable energy resources must be encouraged and developed to increase the demand for renewable energy types. Renewable energy resources are inexhaustible and environmentally friendly, since the energy which is reversed back comes from the sunlight, wind, falling water, waves, geothermal heat, or biomass, in other words they are part of nature. Each type of renewable energy has its own special advantages.

From the early ages, the energy need of the world has been partially compensated by renewable energy types.

Until the mid-1800s, mostly wood was used as an energy source. Also, many large plants and mills were located near the streams to generate electricity during the industrial era in Europe and North America. In the mid-1850s, as the fossil fuel usage, which are mainly coal and oil, increased, production plants were not limited to locate by rivers or streams because instead of water, fossil fuels were started to be used in manufacturing. As a result, industry started to grow up at the locations that are closer to the sources of markets, seaports and raw materials. From $1950^{\text {ee }} \mathrm{s}$ to present, the amount of renewable energy consumption has increased. Increase in amount and variety of renewable energy resources is directly proportional with the increase in population, which leads to increase in energy demand. The renewable energy sources are growing in importance, but combined still make up less than $15 \%$ of world's energy consumption.

There are basically five types of renewable energies.

- Solar Energy

- Wind Energy

- Geothermal Energy

- Hydro Electricity

- Biomass Energy

We are mainly concerned with the Biomass renewable energy source which includes trees, agricultural crops and associated residues like plant fiber, animal wastes, and organic industrial waste. Emission from burning of biomass is carbon dioxide neutral since it absorbs the same amount of carbon dioxide when growing as a plant. Biomass can be used as a solid fuel, or converted into liquid or gaseous forms. It can be used to produce electric power, heat, chemicals, or fuels.

The Jatropha Curcas plant has emerged in recent years to be one of the best viable sources of Biomass renewable energy. The unpredictability of the Fossil fuels commonly used in terms of global prices, diminishing reserves and pollution of the Earth's atmosphere has led to the intense exploration and research for a new and viable renewable source of energy. The Jatropha Curcas plant has shown signs that it is capable of producing clean and safe oil which has properties close to those of the existing fossil fuels and is easily blended with other chemicals to form bio-diesel which can be used in Industrial machines and cars. 
Mechanical screw pressing is the most popular method in the world to separate oil from vegetable oilseeds on small to medium scale. Furthermore, it is possible to manufacture screw presses locally creating additional local employment. Both the oil and the de-oiled press cake obtained using screw presses are free of solvents and other chemicals as opposed to the more efficient solvent extraction method.

Research on mechanical screw presses for pressing oilseeds dates back to 1951 when V.D. Anderson Company patented the first expeller. Ever since considerable efforts have been made to gain better understanding of the processes inside a screw press and improve the oil extraction efficiency. The earlier research was aimed at optimizing process variables like pressure, temperature and rotational speed of the press worm. In addition changes in moisture content and physical, thermal and hydrothermal pretreatment of the seeds were considered in later research. The effect of research outcomes was that oil recovery rates increased from $50 \%$ to $80 \%$ for various oilseeds. Based on previous research various pre-treatments and process variables are considered for the present study.

In recent years, the production of Jatropha curcas has been widely promoted by private enterprises, non-governmental organizations and development agencies as one of the most viable candidates for biodiesel feedstock

The biofuels industry is growing rapidly as a result of high petroleum prices and increasing concerns about global climate change. Ethanol from sugarcane in Brazil and corn in the United States, and biodiesel from rapeseed in European Union countries have been successfully commercialized as petroleum product substitutes with government support.

Thus Jatropha appears to be the potential crop that enables "win-win" relationship among all the actors in the value chain- the biofuel industry to gain profit, society as a whole to achieve mitigation and energy security, and the producers to improve their livelihoods.

\section{BACKGROUND AND LITERATURE REVIEW}

Jatropha is actually a genus of nearly 175 species of shrubs, low-growing plants, and trees. However, discussions of Jatropha as a biodiesel are actually talking about a particular species of the plant, Jatropha curcas, which is also called Barbados nut in Central America and has been known as Physic nut or Pourghere in parts of Africa and Asia. Jatropha curcas is a perennial shrub that, on average, grows approximately three to five meters in height. It has smooth grey bark. The leaves are large and usually pale green and the plant produces flowers. Fruits are produced in winter or throughout the year depending on temperature and soil moisture. The curcas fruit contains $37.5 \%$ shell and $62.5 \%$ seed [1]. Seeds are said to resemble castor in seed shape and black in color. They are $42 \%$ husk and $58 \%$ kernel [1]. Seeds are encased within green capsules in the plant ${ }^{e c}$ s fruit. Seeds often become mature when the capsules change from green to yellow.

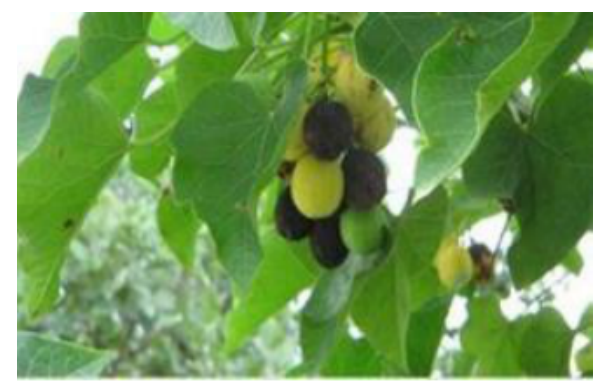

Figure 1 picture of Jatropha mature seeds 


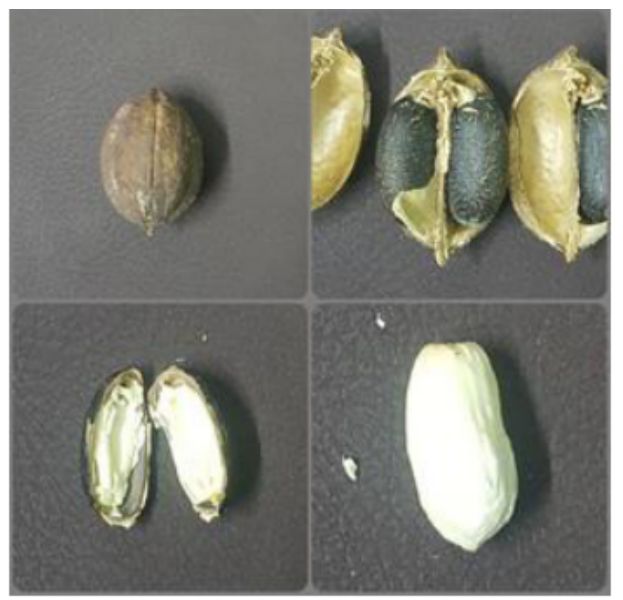

Figure 2

Jatropha curcas can be grown from either seed or cutting. For plants started as seed, germination is achieved within nine days and yielding begins between nine and twelve months. However, effective yields as approximated in numerous studies only can be obtained after about two years.

Generally, multiplication of the Jatropha plant occurs through cuttings rather than by seeds because such a process produces faster results. Since Jatropha is a perennial plant ploughing and planting are not needed regularly. Through estimations the shrub will live approximately forty to fifty years and will produce seeds three times per annum. [2]

The plant is indigenous to parts of Central America and especially Mexico which is believed to be the plant's origin; however it has spread to other tropical and subtropical regions in Africa and Asia. Specifically, Jatropha is being grown in Benin, Brazil, China, Egypt, Ethiopia, Ghana, Guinea, India,

Madagascar, Mali, Mexico, Mozambique, Namibia, Senegal, South Africa, Sudan, Tanzania, Uganda, Zambia, Zimbabwe and most recently Kenya.[3]

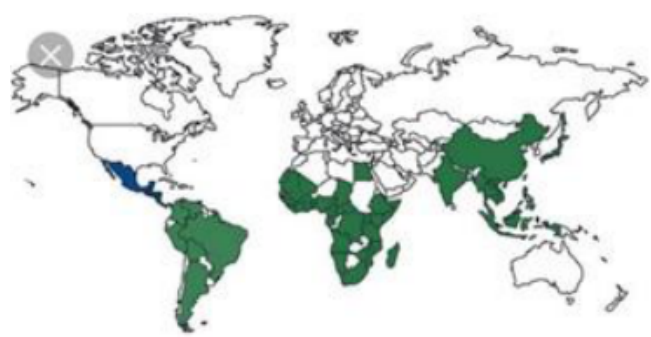

Figure 3 Global indication of the most suitable climate conditions for the growth of Jatropha

As evident by the number of countries in which it is being cultivated, Jatropha curcas grows in a variety of climates and soils. There are reports that the plant can be established in gravelly, sandy, degraded or acidic soil however such a contention lacks scientific consensus [4]. Some studies have highlighted the stunted growth of the plant in areas with heavy metal contamination. There is also some evidence that Jatropha curcas has the possibility for reclaiming marginal soils by re-anchoring the soil with its substantial root system. In theory, the plantes deep roots would recycle nutrients, and reduce the possibility of erosion [5]. Research studies in parts of India have demonstrated that soil structure increased 18 months after Jatropha curcas was planted yet despite this evidence it is widely known biologically that rooting patterns vary based on propagation method (i.e the method by which the plant was cultivated either by cuttings or by seed germination). While plants originating from seeds 
improved soil quality (because they grew a thick primary tap root), plants propagated by cuttings never developed a primary root system and therefore had little effect on soil quality (and were less hardy in sandy areas).

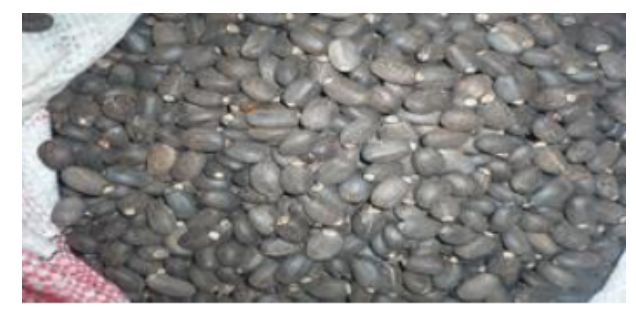

Figure 4 Jatropha seeds

\subsection{Uses of the Jatropha Curcas and its Oil}

There are numerous uses for Jatropha curcas products apart from producing biodiesel and some of these uses are age-old. For instance, Jatropha curcas was traditionally used as a hedging plant in parts of India to protect agriculture and livestock and it was used in some areas in Africa. In addition to the seeds being used for the production of oil as a fuel source or for lighting and cooking, the seeds have also been used as insecticide. Once de-shelled, the glycerin within the almond of the seed can be used to make soap. The pressed cakes that remain after oil has been extracted are often used as organic fertilizer because of their high concentration of nitrogen. In addition, the Jatropha wood and the seed cakes both can be used as firewood or charcoal and also to build traditional houses. Due to the toxicity of the plant, the oil extract could be used as a natural pesticide if cultivated correctly. Jatropha has also been used for much time as a natural remedy and medicine: Jatropha curcas is a little known herbal drug of Unani medicines. It is a potential source of herbal drug in dental complaints. The milky sap of Jatropha curcas is used in Mesoamerica for the treatment of different dermatomucosal diseases. Historically, the leaves of the plant have been used to make tea to treat malaria and the sap is often used by some cultures to stop bleeding. In aggregate, there are numerous uses to the plant when considering it in holistic terms, making it an attractive candidate to many investors and farmers.

\section{OIL EXTRACTION}

Oil has to be extracted in order to be processed and refined. The theoretical maximum amount of oil in a Jatropha curcas seed is $44 \%$ ( $44 \mathrm{~g}$ oil per $100 \mathrm{~g}$ Jatropha seed kernels). There are various methods by which oil can be extracted from the Jatropha curcas seed ranging greatly in both cost and efficiency. The oil extraction methods can be divided into three primary categories:

- Crushing the seeds with a press

- Aqueous enzymatic oil extraction

- Three phase partitioning

\subsection{Oil Extraction Efficiency}

The method we are mainly concerned with at this juncture is by use of the Mechanical Press which is mainly used many small-scale production centers, where oil is extracted using the manual ram-press and the electric screw-press.

The chemical extraction methods which are Aqueous enzymatic oil extraction and Three phase partitioning have shown through preliminary studies that they have a higher yield than 
crushing the seeds with a press which can be clearly seen from the table of oil extraction efficiency.

\subsection{Oil as Fuel}

It is significant to point out that, the non-edible vegetable oil of Jatropha curcas has the requisite potential of providing a promising and commercially viable alternative to diesel oil since it has desirable physicochemical and performance characteristics comparable to diesel. Cars could be run with Jatropha curcas without requiring much change in design.

\subsection{Jatropha in India}

Jatropha is a part of India's goal to achieve energy independence. Jatropha oil is produced from the seeds of the Jatropha curcas, a plant that can grow in wastelands across India. India is keen on reducing its dependence on coal and petroleum to meet its increasing energy demand and encouraging Jatropha cultivation is a crucial component of its energy policy.

\subsection{Indian Railways}

The Indian Railways has started to use the oil (blended with diesel fuel in various ratios) from the Jatropha plant to power its diesel engines with great success. Currently the diesel locomotives that run from Thanjavur to Nagore section and Tiruchirapalli to Lalgudi, Dindigul and Karur sections in Tamil Nadu run on a blend of Jatropha and diesel oil.[6]

\subsection{Karnataka}

Farmers in semi-arid regions of Karnataka are planting Jatropha as it is well suited to those conditions.

Labland Biodiesel is a Mysore-based Private Limited Company. Since the year 2002, the Company is active in Biodiesel and Jatropha curcas-based Research and Development activities headed by its chairman and managing director, Dr. Sudheer Shetty.Jatropha seeds are used in ksrtc, bmtc ,government buses.[8]

\subsection{Tamil Nadu}

Tamil Nadu is aggressively promoting the plantation of Jatropha to help farmers over come the loss due to irregular rains during the past few years. The government has contracted the development of Jatropha in Tamil Nadu in a large scale to four entrepreneurs. Namely M/s Mohan Breweries and Distilleries Limited. M/s Shiva Distilleries Limited, M/s Dharani Sugars and Chemicals Limited and M/s Riverway Agro Products Private Ltd. Currently the firms have cultivated the plant in about 3 square kilometres as against the goal of $50 \mathrm{~km}^{2}$. The government of Tamil Nadu has also abolished purchase tax on Jatropha, but presently government has announced to reduce the $7.5 \%$ tolgate charges to $2.5 \%$

\subsection{Rajasthan}

Jatropha is ideally suited for cultivation in Rajasthan as it needs very little water which is scarce in Rajasthan. Jatropa plantations have been undertaken in Udaipur, Kota, Sikar, Banswara, Chittor and Churu districts. In the Udaipur district, Jatropha curcas is planted in agroforestry formats with food or cash crops on marginal lands (in India often called waste lands). As its leaves are toxic and therefore non-palatable to livestock, they remain intact in their sapling stage, unlike most other tree saplings. These Jatropha Seeds are very much favourable for the Germination. Udaipur is the major supplier of the Jatropha Seeds especially for the Germination. Many companies and Govt are taking interest to collect best seeds from Udaipur. Bulk Agro (I) Pvt Ltd is the elite of the suppliers. 


\subsection{Maharashtra}

In September 2007, the Hindustan Petroleum Corporation Limited (HPCL) joined hands with the Maharashtra State Farming Corporation Ltd (MSFCL) for a jatropha seed-based bio-diesel venture. As part of the project, jatropha plants would be grown on 500 acres $\left(2 \mathrm{~km}^{2}\right)$ in Nashik and Aurangabad.[9] In November 2005, the Maharashtra Government aimed to cultivate jatropha on $600 \mathrm{~km}^{2}$ in the state, with half the land going to the public sector and the other half to the private sector.[10] On 1 July 2006, Pune Municipal Corporation took the lead among Indian cities in using bio-diesel from jatropha in over 100 public buses.[11]

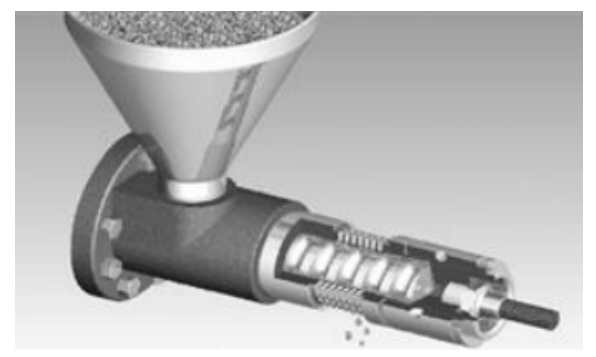

Figure 5

\section{ADVANTAGES OF USING JATROPHA OIL}

- The higher cetane number of biodiesel compared to petro-diesel indicates potential for higher engine performance. Tests have shown that biodiesel has similar or better fuel consumption, horsepower, and torque and haulage rates as conventional diesel.

- The superior lubricating properties of biodiesel increases functional engine efficiency.

- Their higher flash point makes them safer to store.

- The biodiesel molecules are simple hydrocarbon chains, containing no sulfur, or aromatic substances associated with fossil fuels.

- They contain higher amount oxygen (up to $10 \%$ ) that ensures more complete combustion of hydrocarbons.

- Biodiesel almost completely eliminates lifecycle carbon dioxide emissions. When compared to petro-diesel it reduces emission of particulate matter by $40 \%$, unburned hydrocarbons by $68 \%$, carbon monoxide by $44 \%$, sulphates by $100 \%$, polycyclic aromatic hydrocarbons (PAHs) by $80 \%$, and the carcinogenic nitrated PAHs by $90 \%$ on an average.[12]

\section{JATROPHA SEED OIL EXTRACTION AND CAKE DRAINAGE SYSTEMS}

\subsection{Jatropha Seed Oil Extraction}

The major aim of all screw press machines is to generate compression for extraction of oil in the seeds but there are several differences in design of the pressing shaft and drainage mechanism principles. The oil presses used in industry are described in following subsections followed by the mechanisms used in cake drainage.

\subsubsection{Komet Oil Presses}

In this type of screw press, oil leaks out from the holes as represented. The holes are drilled on the vessel. The oil drainage hole has a larger diameter outside the vessel and this diameter continues up to few millimeter thickness of the vessel. This small thickness of the vessel is 
drilled with a smaller diameter. Most probably, the reason for the short length of the smaller hole is to prevent it from choking with cake. Also, oil drainage zone is far from the cake drainage zone. At the cake drainage zone, cake pressure is maximum. So, if the oil drainage holes were drilled close to the cake drainage zone, then the holes can be choked with cake easily. Dry cake extrudes from the nozzle. At the cake drainage, there is a heating system. Heat provides higher oil yield and lower residual oil in the cake. In this type of screw presses, different kinds of seeds can be compressed by changing the nozzle and the rotational speed of the screw shaft. [13]

\subsubsection{Rose downs Oil Presses}

A complete system of a Rosedowns screw press is represented in Figure4.3. The system is divided into subgroups as:

\subsubsection{Main Gearbox}

It transmits the power of the motor to the screw shaft. Gearboxes should be separated as far as possible for the hot and dirty environment of the pressing sections. The feeding section of the screw shaft is the cooler and lower pressure end of the press. Therefore the best choice for the drive position is the feeding end of the screw shaft. [14]

\subsubsection{Feeding Section}

It is composed of mainly three parts which are the feed inlet, the horizontal feeder and vertical feeder. Seeds are poured into the feed inlet. Then with the help of the variable speed drive of the horizontal feeder, the flow of feed is controlled. Vertical feeder prevents bridging in the cage inlet and ensures that the seeds pass into the vessel. [15]

\subsubsection{Bearings}

There are two kinds of bearings. One of them is called thrust bearing and it carries the thrust loads generated by the press. The other bearing is the discharge end bearing and it is used for supporting the shaft when there is no load or light load inside the press. Without this bearing, the screw shaft can hit inside the walls of the vessel. [15]

\subsubsection{Cages}

For longer presses, the cage is divided into two parts in order to keep the main cage to a more manageable size for maintenance operations. The inside cage is composed of lining bars separated by spacers. The size of the spacers can be altered for different kinds of seeds by changing the drainage gaps. [15]

\subsubsection{Screw Shaft}

The screw shaft is the key functional part of a screw press. The screw shaft has multi-stage compressions in order to reduce the required pressure. In recent years the multi-stage, lower compression screw shaft has led to significant improvements in performance, wear life and power consumption. As represented in figure4.2, at the compression stage, the screw shaft becomes tapered where the inside vessel diameter decreases. Therefore, pressure increases at the decreased annular area which results in compression of seeds. [15]

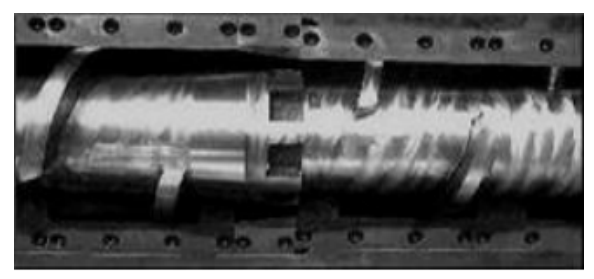

Figure 6

Detailed views of the screw shaft of Rosedowns Screw Presses [15] 


\subsubsection{Vincent Screw Presses}

A screw of progressively reducing pitch rotates inside a cylindrical perforated screen. Material entering the hopper is subjected to gradually increasing pressure as it moves toward the exit end of the press, forcing the liquid phase to extrude through the screen. Two resistor teeth fit in each interruption of the turn as seen in Figure. This interruption prevents jamming. [16]

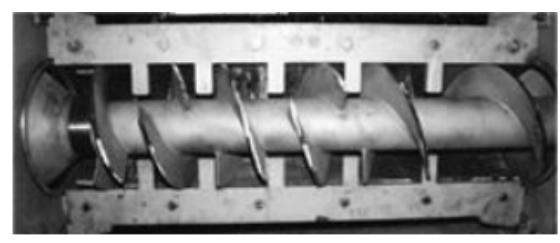

Figure 7

Screw with Resistor Bars manufactured by Vincent Corporation

\subsubsection{Strainer type screw Presses}

In strainer type of screw presses, oil rushes out from the strainers which are made up of flat plates mounted through the screw shaft. By rotating the arm which is at the right end of the screw press in Figure4.5, the screw shaft can be displaced forward or backward to adjust the thickness of the cake which is extruded at the left end of the screw press. Accordingly, different kinds of seeds can be compressed also by changing the rotational speed.[17]

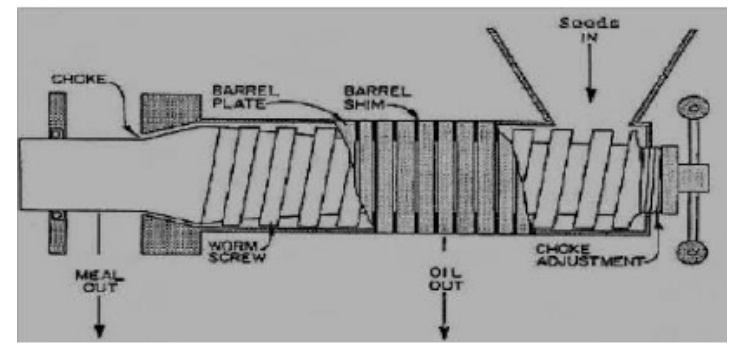

Figure 8 Strainer Type Screw Press

\section{CAKE DRAINAGE SYSTEMS}

The common property of cake drainage systems in screw presses is the adjustability of the cake drainage opening. Narrower openings result in low residual oil content in the cake. Also, the opening size depends on the type of the seed.

During our research, various types of cake drainage systems are considered. Some of them are used in conventional screw presses as presented.

Working principles of these cake drainage systems are presented in the subsections.

\subsection{Nozzle Cake Drainage System}

Generally, in small types of screw presses, nozzle type choke mechanism is used. In Komet Oil Presses, this type of a choke mechanism is used [12]. In nozzle type choke mechanisms in figure4.6, one end of the screw shaft is free and the other end has two bearings. The screw shaft is short enough to compensate any deformation arising from buckling.

Seeds continue to accumulate at the end of the screw until the maximum pressure has been reached. During compression, oil part of the seeds leaks from the filter and the left cake starts to extrude out from the nozzle, at the end of the screw. Besides, the required maximum pressure can be provided by adjusting the nozzle diameter. 
In this type of choking mechanism, the maximum pressure at the end of the screw pushes the screw backward. The resultant force is the multiplication of the axial component of the maximum pressure and the circular area of the screw.

Since the application area of the back force is comparatively larger than in conical type of choke mechanisms, bearing which carries the axial back force should be larger in this type of systems. Another disadvantage for this choking system is the probability of a blockage at the entrance of the nozzle.

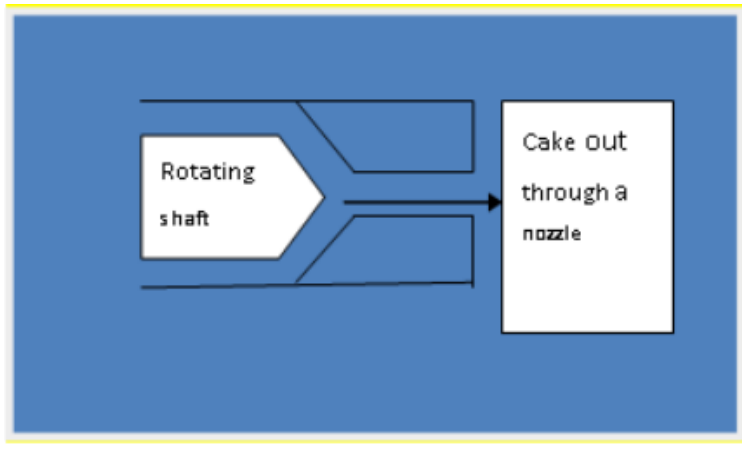

Figure 9

\subsection{Conical Drainage System}

This type of a system in figure 4.7 is both practical and economical when compared with the equivalent systems. In Tiny tech Tiny Oil Mills, this type of a choke mechanism is used [18]. The maximum pressure and the cake thickness can be changed by adjusting axial displacement of the screw shaft forward and backward in order to achieve the required pressure. The force pushing the screw backward is relatively less here when compared with the nozzle type choke mechanism since the effective pressure area is less than the normal cross section

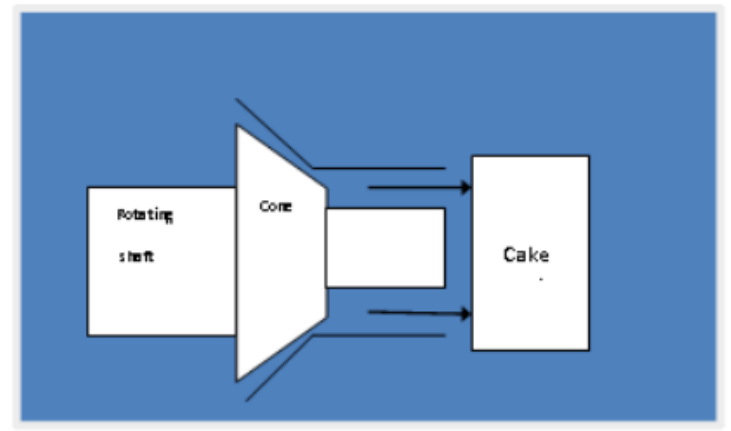

Figure 10

\section{PRELIMINARY AND DETAILED DESIGN OF THE OIL EXTRACTION MACHINE}

\subsection{Preliminary Design}

In this section, design tree and block diagram of the selected system, separation of the system into subsystems and specifications of these subsystems are given. 


\subsubsection{Skeleton}

Skeleton is composed of the stand and the bearing bushings. It carries the main body (vessel, shaft and hopper). The screw shaft is bedded with the bearings. The bearings are elevated to a height where the screw shaft can rotate concentrically inside the vessel.

The oil tank is placed just below the main body onto which the oil drains out after it has been squeezed out of the Jatropha seeds by the shaft.

\subsubsection{Main Body}

The main body is composed of three parts which are the screw shaft, the vessel and the hopper.

Their functionalities are described in the following subsections.

\subsubsection{Screw Shaft}

The seeds are compressed in two ways. First way of compression occurs by the continuous feeding of the seeds into the system. Newly fed seeds compress the seeds which are already present in the system Another way compression takes place is between the inside surface of the vessel and inside surface of the screw shaft. As the depth of the thread decreases continuously, the distance between thread surfaces decrease as a result the seeds volume reduce as oil is drained out. For these reasons, this type of screw shaft configuration is evaluated as the most appropriate one for this project.

Screw shaft rotates inside the vessel. There is a small clearance between the vessel and the screw shaft. This small clearance is necessary for avoiding the seeds penetrating between the outside diameter of the screw shaft and the inside surface of the vessel. In such a case, friction force between the screw shaft and vessel increases, and required torque becomes higher.

The screw shaft pitch reduces down the vessel as a result more pressure is applied on the seeds. The seeds are fed at where the thread depth is maximum. As the seeds pass through the screw, swept volume of each turn decreases. Under high pressure, oil is separated from the compressed seeds and drains back to the previous turns at where the pressure is lower. Since cake has no such fluidity property like oil, it continues to the end of the screw shaft and drained out as flakes. At the end of the last thread on the shaft there is a cone which allows a narrow Cake to drain out radially between it and the vessel surface. By adjusting the screw shaft in the longitudinal direction, the gap size of the cake drainage can be reduced or increased. As the gap size is smaller, the residual oil content of the cake becomes lower, because the compressed seed is applied higher pressure

\subsubsection{Vessel}

The vessel has a rectangular hole which allows the seeds from the hopper into the beginning of the screw shaft where the thread pitch is maximum. It has holes all round from which oil drains out into the tank.

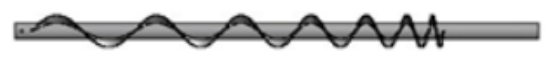

Figure 11

The oil drainage zone is slightly far from the cake drainage zone or in other words, the maximum pressure zone. The reason is that, these small holes are filled and choked with compressed cake at high pressure levels. However, on the mid zone of the vessel, pressure of the cake is not that much high and oil can easily pass through these holes. 


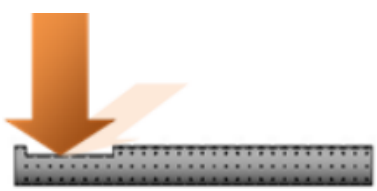

Figure 12

\subsubsection{Hopper}

Hopper is used to carry and canalize the seeds into the screw press. Feeding does not need any energy; gravity is sufficient for feeding. It is a stationary part and mounted onto the vessel. The passage hole of the hopper is large enough in order to prevent choking of the seeds into the vessel.

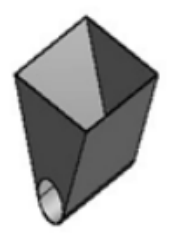

Figure 13

\subsubsection{Tank}

This is where the squeezed oil is drained to awaiting transfer to the storage containers. It is placed just below the vessel and it contains lid which has many holes.

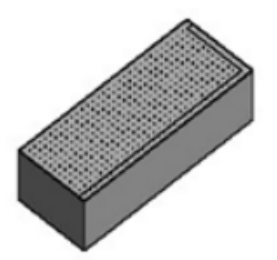

Figure 14

\subsubsection{Cone}

The maximum pressure and the cake thickness can be changed by adjusting axial displacement of the screw shaft forward and backward in order to achieve the required pressure. As a result the amount of cake out of the cone is adjusted hence the maximum amount of fuel can be obtained.

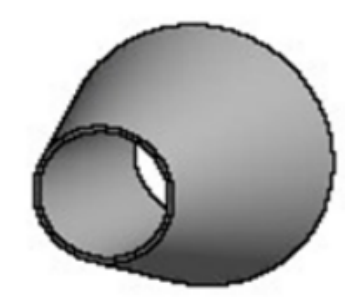

Figure 15 


\subsubsection{Drive system}

This system comprises of a motor two horsepower, 2 pulleys $(10 \mathrm{~cm}$ and the other $250 \mathrm{~cm}$ diameter) and a v belt. The $250 \mathrm{~cm}$ pulley is connected onto the pressing shaft while the other $10 \mathrm{~cm}$ pulley is connected onto the motor shaft. The pulley connected to the pressing shaft is 25 times the diameter of the pulley connected to the motor shaft.

Table 1

\begin{tabular}{|c|c|}
\hline Specifications & Amount \\
\hline Capacity & $15 \mathrm{~kg} / \mathrm{h}$ \\
\hline Screw length & $650-750 \mathrm{~mm}$ \\
\hline Screw diameter & $35-45 \mathrm{~mm}$ \\
\hline Average helix angel & $5-8$ degrees \\
\hline Channel height & $7-10 \mathrm{~mm}$ \\
\hline Channel width & $7-9 \mathrm{~mm}$ \\
\hline Rpm of Screw & $30-70($ variable $)$ \\
\hline Power of motor & $1 \mathrm{hp}$ \\
\hline
\end{tabular}

\subsection{Biodiesel Production}

Oil content varies from $28 \%$ to $30 \%$ and $80 \%$ extraction, one hectare of plantation will give 400 to 600 litres of oil if the soil is average.[19]

The oily seeds are processed into oil, which may be used directly ("Straight Vegetable Oil") to fuel combustion engines or may be subjected to transesterification to produce biodiesel.] Jatropha oil is not suitable for human consumption, as it induces strong vomiting and diarrhea.

When jatropha seeds are crushed, the resulting jatropha oil can be processed to produce a high-quality biofuel or biodiesel that can be used in a standard diesel car or further processed into jet fuel, while the residue (press cake) can also be used as biomass feedstock to power electricity plants, used as fertilizer (it contains nitrogen, phosphorus and potassium). The cake can also be used as feed in digesters and gasifiers to produce biogas.[20]

\subsection{Transesterification}

There are several forms of biofuel, often manufactured using sedimentation, centrifugation, and filtration. The fats and oils are turned into esters while separating the glycerin. At the end of the process, the glycerin settles and the biofuel floats. The process through which the glycerin is separated from the biodiesel is known as transesterification. Glycerin is another by-product from Jatropha oil processing that can add value to the crop. Transesterification is a simple chemical reaction that neutralizes the free fatty acids present in any fatty substances in Jatropha. A chemical exchange takes place between the alkoxy groups of an ester compound by an alcohol. Usually, methanol and ethanol are used for the purpose. The reaction occurs by the presence of a catalyst, usually sodium hydroxide $(\mathrm{NaOH})$ or caustic soda and potassium hydroxide $(\mathrm{KOH})$, which forms fatty esters (e.g., methyl or ethyl esters), commonly known as biodiesel. It takes approximately $10 \%$ of methyl alcohol by weight of the fatty substance to start the transesterification process.[21]

The transesterification process using methanol can be expressed by the simplified equation shown below:

Oil or Fat (Triglycerides) + Methanol $=$ Methyl Ester + Glycerol 


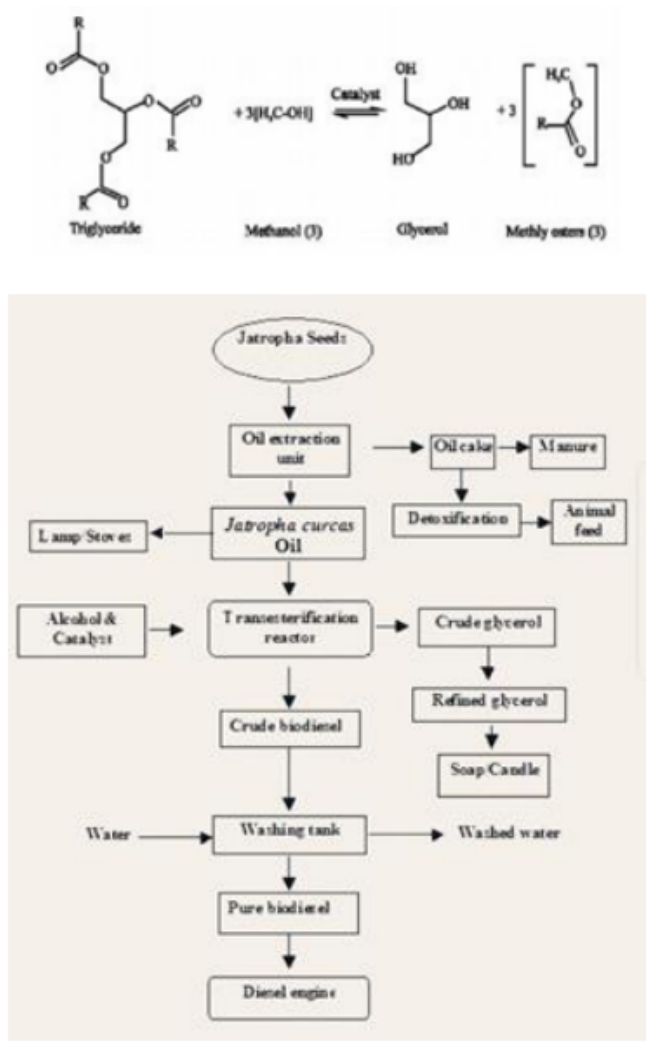

Figure 16 reference [22]

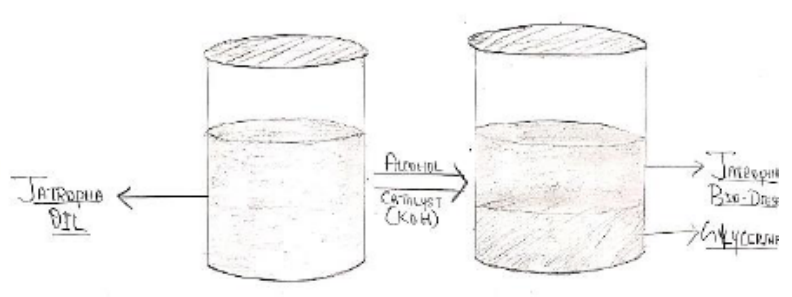

Figure 17

\subsection{Jet Fuel}

Aviation fuels may be more widely replaced by biofuels such as jatropha oil than fuels for other forms of transportation. There are fewer planes than cars or trucks and far fewer jet fueling stations to convert than gas stations.[23] To fulfil the yearly demand for aviation fuel, based on demand in 2008 (fuel use has since grown), an area of farmland twice the size of France would need to be planted with jatropha, based on average yields of mature plantations on reasonably good, irrigated land.[24]

On December 30, 2008, Air New Zealand flew the first successful test flight from Auckland with a Boeing 747 running one of its four Rolls-Royce engines on a 50:50 blend of jatropha oil and jet A-1 fuel.[23][25] In the same press release, Air New Zealand announced plans to use the new fuel for $10 \%$ of its needs by 2013 . At the time of this test, jatropha oil 
was much cheaper than crude oil, costing an estimated $\$ 43$ a barrel or about one-third of the June 4, 2008 closing price of $\$ 122.30$ for a barrel of crude oil.[26]

On January 7, 2009 Continental Airlines successfully completed a test flight from Houston, Texas using a 50/50 mixture of algae/jatropha-oil-derived biofuel and Jet A in one of the two CFM56 engines of a Boeing 737-800 Next Generation jet. The two-hour test flight could mark another promising step for the airline industry to find cheaper and more environmentally friendly alternatives to fossil fuel.

On April 1, 2011 Interjet completed the first Mexican aviation biofuels test flight on an Airbus A320. The fuel was a 70:30 traditional jet fuel biojet blend produced from Jatropha oil provided by three Mexican producers, Global Energías Renovables (a wholly owned subsidiary of U.S.-based Global Clean Energy Holdings), Bencafser S.A. and Energy JH S.A. Honeywell's UOP processed the oil into Bio-SPK (Synthetic Paraffinic Kerosene).[n] Global Energías Renovables operates the largest Jatropha farm in the Americas.[27]

On October 28, 2011 Air China completed the first successful demonstration flight by a Chinese airline that used jatropha-based biofuel. The mixture was a 50:50 mix of conventional jet fuel blended with jatropha oil from China National Petroleum Corp. The 747400 powered one of its four engines on the fuel mixture during the 1-hour flight around Beijing airport.[28]

On August 27, 2018 SpiceJet completed the first successful test flight by an Indian airline which used jatorpha based biofuel. The ratio of conventional jet fuel to jatropha oil was 25:75.[29]

\section{CONCLUSION}

Countries of South-East Asia, such as Malaysia, they are going to start the establishment of Jatropha plantations assuming that Jatropha will be the main resource for biodiesel production. This paper presents the design and fabrication of an efficient Jatropha oil expelling machine. Further carrying out transesterification process on Jatropha oil to get Jatropha biodiesel

\section{REFERENCES}

[1] Singh, R.N., D.K. Vyas, N.S.L. Srivastava and Madhuri Narra. "SPRERI Experience on Holistic Approach to utilize all Parts of Jatropha Curcas Fruit for Energy." Renewable Energy: in press: 1-6. 2007

[2] Van Eijck, Janske and Henny Romijn. "Prospects of Jatropha Biofuels in Tanzania: An analysis with Strategic Niche Management." 2008. Energy Policy 36: 311325.

[3] Henning, R. "Combating Desertification: The Jatropha Project of Mali, West Africa, in: The Arid Lands Newsletter". 1996. Accessed at: http://ag.arizona.edu/OALS/ALN/aln40/jatropha.html

[4] Openshaw, Keith. "A Review of Jatropha Curcas: an Oil Plant of unfulfilled Promise." Biomass and Bioenergy 19: 1-15. 2000

[5] Kumar, Ashwani and Satyawati Sharma. "An Evaluation of Multipurpose Oil Seed Crop for Industrial uses (Jatropha Curcas L.): A Review." Industrial Crops and Products: in press: 1-8. 2008

[6] "Rlys to Plant Jatropha for Captive use". The Hindu Business Line. Retrieved 17 September 2006.

[7] Barta, Patrick (24 August 2007). "Jatropha Plant Gains Steam in Global Race for Biofuels". The Wall Street Journal. Retrieved 1 April 2008. Until recently, B.K. Nagendrappa didn't Care much at all about Jatropha, an Ugly Wild Green Shrub that Thrives in India. Now, the Coconut grower hopes to Plant as many as 12 acres (4.9 ha) of the stuff on his land near Bangalore. 2007 
[8] http://www.lablandbiodiesel.com Labland Biodiesel. Retrieved 21 June 2008

[9] "HPCL, Maharashtra tie up for bio-diesel venture". The Hindu Business Line. Retrieved 8 July 2006.

[10] "Maharashtra to offer $300 \mathrm{~km}^{2}$ to Private Sector for Jatropha Cultivation". The Hindu Business Line. Retrieved 8 July 2006.

[11] "Pune take the Lead in using Bio-Diesel for Running 105 Buses". Indiadaily.com. Archived from the Original on 23 March 2007. Retrieved 8 July 2006.

[12] Jatropha Curcas - Multipurpose Plants and Source of Energy for Future by, Edgar Munch and Joachim Kiefer (GTZ).

[13] Webpage of IBG Monforts Oekotec GmbH \& Co. KG, http://www.oekotec.ibg-monforts.de, Accessed at 18.04.2012

[14] Webpage of De Smet Rosedowns, www.rosedowns.co.uk, Accessed at 18.04.2012

[15] http://vincentcorp.com, Accessed at 20.04.2012

[16] Ferchau, E., "Equipment of Decentralized Cold Pressing of Oil Seeds", 2000, Webpage of Folkecenter for Renewable Energy, www.folkecenter.dk

[17] Webpage of Tinytech Plants, http://www.tinytechindia.com/oil.htm, Accessed at 20.04.2012

[18] Gichuki, F.N. (2000a) Makueni District Profile: Farm Development, 1989-98"e, Drylands Research Working Paper No. 1. Drylands Research, Crewkerne, United Kingdom.

[19] "Jatropha Curcas Plant". www.svlele.com.

[20] Poison Plant Could Help to Cure the Planet Times Online, 28 July 2007.

[21] Nahar, K. and Ozores-Hampton, M. (2011). Jatropha: An Alternative Substitute to Fossil Fuel. (IFAS Publication Number HS1193). University of Florida, Institute of Food and Agricultural Sciences. Electronic Data Information Source. Retrieved (12-17-2011).

[22] D. Ramesh, A. Samapathrajan, P. Venkatachalam, Production of Biodiesel from Jatropha Curcas Oil by using Pilot Biodiesel Plant. The Jatropha online Journal. 18 (9), 1-6, 2006

[23] Kanter, James. "Air New Zealand Flies on Engine with Jatropha Biofuel Blend". The New York Times. December 30, 2008

[24] http://www.davidstrahan.com/blog/?p=170; accessed 11 November 2017

[25] Enviro.aero December 30, 2008. Air New Zealand Jatropha Flight, update 4 Accessed October 13, 2012.

[26] Ray, Lilley. "NZ Airline Flies Jetliner Partly Run on Veggie Oil". www.latimes.com. Retrieved 01-22, 2011

[27] Erin Voegele for Biodiesels Magazine. April 8, Mexico Hosts Successful Biofuels Test Flight, 2011

[28] "Air China Conducts First Biofuel Test Flight-Sci-Tech-chinadaily.com.cn". www.chinadaily.com.cn.

[29] www.indianexpress.comhttps://indianexpress.com/article/business/aviation/spicejet-operatesindias-first-biofuel-powered-flight-5326913/.

[30] Anand Kalani and Rita Jani, Comparative Study of Full Journal Bearing with Bio Lubricants Jatropha Oil, Castor Oil, Neem Oil And Mineral Oil (SAE 20w50). International Journal of Mechanical Engineering and Technology, 6(6), 2015, pp. 127-131

[31] Prof. A.V. Mehta, M. G. Joshi, G. D. Patel and Saiyad M J. I., Jatropha Oil with Exhaust Heat Recovery System in 4 Stroke Single Cylinder Diesel Engine. International Journal of Mechanical Engineering and Technology, 4(2), 2013, pp. 512-520

[32] T. Ohm Prakash, M.V.S. Murali Krishna and P. Ushasri, Studies on Exhaust Emissions of Diesel Engine with Ceramic Coated Combustion Chamber with Carbureted Methanol and Crude Jatropha Oil. International Journal of Mechanical Engineering and Technology, 5(6), 2014, pp. 80-89 